\title{
Josua Reichert: Die Stuttgarter Drucke 1971-1973
}

Der 1970 fertiggestellte Neubau der Württembergischen Landesbibliothek wird in der Wirkung seiner Innenräume ganz wesentlich von den großformatigen Drucken, den sogenannten Stuttgarter Drucken, des Künstlers Josua Reichert geprägt.

Erste größere Aufmerksamkeit erreichte der 1937 in Stuttgart geborene Künstler 1960 in der Ausstellung zum literarischen Expressionismus im SchillerNationalmuseum in Marbach, wo seine großformatigen Gedichtfahnen - monumentale Text-Bilder - die Besucher beeindruckten. Vielleicht waren es diese meterhohen Drucke, die bei dem damaligen Direktor der Württembergischen Landesbibliothek Wilhelm Hoffmann das Interesse an dem jungen Künstler weckten. Zumindest wurden seit Anfang der 1960er Jahre Arbeiten des Künstlers für die Landesbibliothek erworben. Und als Ende der 1960er Jahre der Baubeginn für den geplanten Bibliotheksneubau näher rückte und damit die Frage nach der künstlerischen Gestaltung aufkam, fiel die Wahl auf Josua Reichert. Dieser empfand die damals vorherrschende Umsetzung von Kunst am Bau-Reliefs, Fresken, Mosaike, Glasfenster - als unbefriedigend beengt und konnte die eingesetzte Kunstkommission davon überzeugen, dass auch große gerahmte Drucke die Bedingung erfüllten, ein fest mit dem Bauwerk verbundenes Kunstwerk zu sein. Auch dass der geplante Neubau kein herkömmlicher Bibliotheksbau sein werde und so gut wie über keine Wände zur Hängung von Bildern verfügen würde, schreckte den Künstler nicht. Bei der Wahl der Texte gab es keine Vorgaben und so konnte sich Reichert bei der Erarbeitung des Konzepts frei bewegen und dachte von Anfang an in einem Zeit und Kontinente überspannenden Bogen. Er wählte Schriften, Gedichte und Texte aus rund 2.500 Jahren der Weltliteratur, wobei inm nach eigener Aussage die Texte "in erster Linie ein Vorwand für die Typografie" waren.

Sechs Buchstabenbilder - arabisches Vav, hebräisches Mem, lateinisches P mit $\mathrm{Q}$, kyrillisches Jat, lateinisches $V$, griechisches Psi - sollten den Aus-

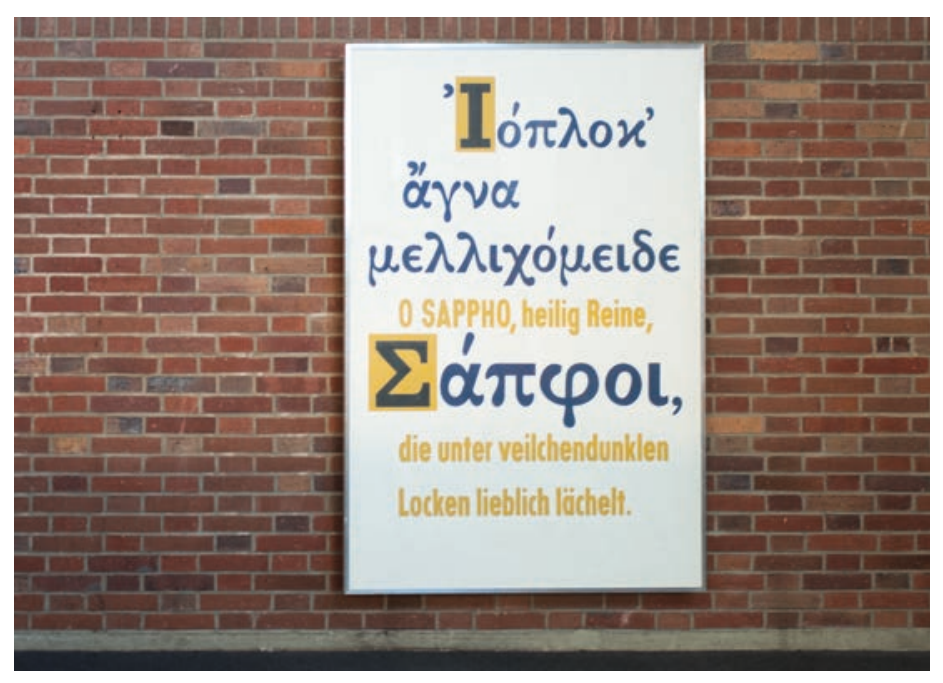

Abb. 1: Stuttgarter Drucke: Gedichtfragment 94D der Sappho

gangspunkt für die Entfaltung der Schriftbilder im gesamten Bibliotheksbau bilden. Reichert schrieb später dazu: „jeder buchstabe sollte ein keimling sein, aus dem verschiedenartigste typografie hervorgeht gedichtblätter, prosaseiten, sprüche, wörter, sätze, palindrome, typenkonstellationen, buchstabenbilder, kompositionen: von hier aus sollten sie sich durch das gebäude verbreiten. ich dachte gleich weiter, bezog gedanklich die umliegenden bauten mit ein, die gebäude in der stadt, gebäude in anderen städten." Reichert befand sich „inmitten eines strudels, um mich herum kreisten die buchstaben, die dichter, die schriften, die bücher und fotos." Er studierte die verschiedenen Schriften und Alphabete und die Regeln der arabischen und hebräischen Typografie. Er kaufte Metalllettern, bestellte Holztypen in England, ließ weitere Schriften schneiden und Plexiglastypen sägen und schnitt selbst Formen aus PVC. Der Druckprozess der 36 großformatigen Blätter - das größte misst $120 \times 280 \mathrm{~cm}$ - gestaltete sich nicht weniger aufwändig. Gedruckt wurden die Blätter fast ausnahmslos als Hand- bzw. Reibedrucke vom Künstler selbst in seiner Werkstatt, wo er die Druckformen auf einem großen Tisch montierte

1) Die Angaben und Zitate sind folgenden Publikationen entnommen: Reichert, Josua: Die Stuttgarter Drucke von Josua Reichert, Meran: Offizin "S.", Siegfried Höllrigl, 2012.

Pfäfflin, Waltraud; Maurice, Klaus: Josua Reichert Werkverzeichnis 1959-1995: Mit Anmerkungen des Künstlers zu seinen Werkgruppen, Ostfildern-Ruit: Hatje, 1997. 
